\title{
ESCENAS DE LECTURA. LA LECTURA COMO INTERRUPCIÓN
}

\author{
Reading Scenes. Reading as interruption
}

\author{
Nicolás Garayalde
}

\begin{abstract}
RESUMEN
En este ensayo nos proponemos indagar la figura de la interrupción de la lectura con el objetivo de ofrecer una definición de la lectura como interrupción. Evocada en diversas ocasiones por diferentes críticos, representada numerosas veces en la historia de la pintura, la figura de la interrupción de la lectura aparece retratada también en la literatura donde creemos posible encontrar elementos para considerar la lectura como interrupción. Para ello, nos detendremos en lo que llamaremos tres escenas de lectura (Proust, Saer, Cortázar) interrogando allí lo que remite a la interrupción, a las fronteras entre la vida y la literatura, entre el texto y el lector, entre la realidad y la ficción, buscando ofrecer una posible definición de la lectura.
\end{abstract}

Palabras clave: lectura, interrupción, escenas de lectura, vida, literatura.

\begin{abstract}
In this essay we propose to investigate the figure of the interruption of reading in order to offer a definition of reading as interruption. Evocated on several occasions by different critics, represented numerous times in the history of painting, the figure of the interruption of reading is also portrayed in literature where we believe it is possible to find elements that examine reading as interruption. For this, we will focus on what we will call three reading scenes (Proust, Saer, Cortázar) that aims to explore what we define as the interruption and to investigate the borders between life and literature, between text and reader, between reality and fiction, seeking to offer a possible definition of reading.
\end{abstract}

Key Words: Reading, interruption, reading scenes, life, literature.

\section{Introducción: la lectura interrumpida}

En el museo Marmottan Monet, en París, se exhibe una pintura de Camille Corot de 1870 que se titula La lecture interrompue: una mujer, con un vestido italiano, deja caer un libro que apenas sostiene con la mano izquierda, mientras apoya su cabeza -ligeramente inclinadaen su brazo derecho, manteniendo una expresión melancólica, subrayada por la abstracción del color que redunda en los sepias.

\footnotetext{
${ }^{1}$ Universidad Nacional de Córdoba. Profesor de Teoría Literaria, Facultad de Filosofía y Humanidades. Becario postdoctoral de CONICET. Argentina.

Correo electrónico: nicolas_rio3@hotmail.com
}

Recepción: 29/10/2018. Aceptación: 24/11/2018. 


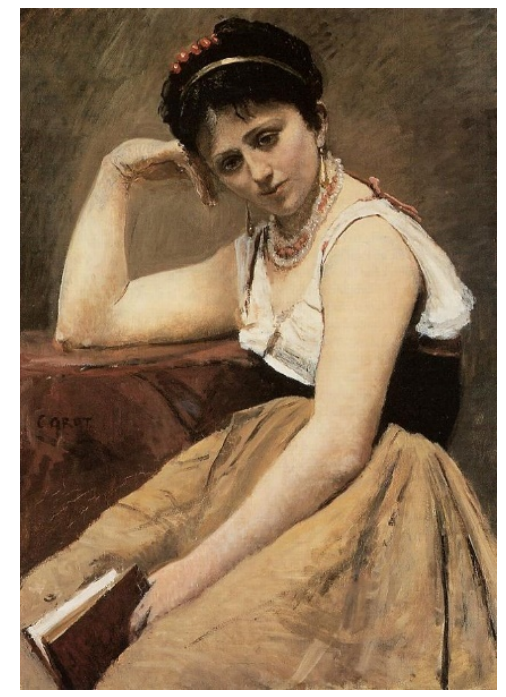

\section{La lecture interrompue (1870), de Camille Corot}

¿De qué se trata en ese momento preciso en el que la lectora abandona el libro y permanece con la mirada perdida? El cuadro de Corot no es único en su especie en cuanto al tema trabajado. Woman Reading (1871), de James Gordon; L'arlesienne (1888), de Vincent Van Gogh; Mujer con libro (1932), de Pablo Picasso; Mujer leyendo (1998), de Fernando Botero. En todas estas obras, con independencia de sus estilos, la escena se repite: la interrupción de la lectura, la mirada perdida por algo que el libro ha evocado.

¿Qué nos dice sobre la lectura esta interrupción? ¿Qué es lo que se interrumpe cuando estas lectoras levantan la cabeza y dirigen la mirada hacia un afuera del libro? ¿De dónde vienen y a dónde van en esa transición que parece sucederse entre un mundo -el de la ficción- y otro -el de la vida-?

A estas preguntas quisiéramos responder con una afirmación contundente que este ensayo buscará sostener a título de hipótesis: la lectura es su interrupción. ¿Qué querría decir esta definición?

La lectura como interrupción. Este sintagma podría quizás pensarse remitiendo la pregunta a la propia literatura, deteniéndonos en lo que podemos llamar escenas de lectura: episodios literarios en los que la lectura entra en acto. Así, trabajando, operamos de manera semejante a Paul de Man cuando se pregunta en Allegories of Reading:

¿Qué nos dice $\grave{A}$ la recherche du temps perdu sobre la lectura? Considero este interrogante en el modo más literal y de hecho naif posible, al leer un pasaje que nos muestra a Marcel compenetrado en el acto de leer una novela (1979, p. 57). 
De Man aclara inmediatamente que no podemos a priori pensar que deteniéndonos en una escena de lectura en Proust accederemos a lo que en su obra se dice sobre la lectura, porque el sentido leído no está destinado a coincidir con el sentido enunciado. De tal modo que una escena de lectura no tiene ningún privilegio sobre otras para decirnos algo acerca de la lectura. Concedamos a de Man esta afirmación, por lo cierto densamente argumentada a lo largo de su libro. Pero estas escenas, aún sin su privilegio, son una buena ocasión, como cualquier otra, para indagar la lectura y su interrupción, la lectura como interrupción. No por casualidad el propio de Man dedica tantas páginas al momento en que Marcel se encierra en su cuarto a leer una novela durante un día de verano. En ciertos casos, incluso, pareciera existir un privilegio en las representaciones de la lectura respecto de lo que pueden decirnos sobre ella. Al menos en su aspecto sociológico, tal como Asunción Bernández lo señala en su estudio sobre las representaciones de la lectura en la pintura del Siglo de Oro español: "Las fuentes iconográficas pueden hacernos avanzar en la hipótesis de que en la Edad Media y el Renacimiento las mujeres leían más de lo que podríamos imaginar contando las posesiones de libros que han quedado reflejados en distintos cómputos" (2007, p. 70).

En todo caso, dejemos a un lado toda consideración de un privilegio metodológico y consideremos la ventaja, subrayada por Pierre Bayard (2004) al cuestionar el psicoanálisis aplicado a la literatura, de buscar en esta última elementos de teorización, es decir, no ir a la literatura con el objetivo de rastrear lo que la teoría hipotetiza; antes bien, invertir la dirección y rastrear en la literatura un trabajo teórico que interpele el objeto sobre el cual queremos indagar, para el caso, la lectura. Por ello, nos concentraremos en este artículo en tres escenas literarias que tienen en común representar la lectura a partir de la figura de la interrupción. De modo que nos permitan pensar esta figura como una vía para definir el concepto de lectura.

Como la persona lectora habrá ya sospechado, estas escenas no dejarán de interpelar la figura de la interrupción que ha sido elaborada en un conocido ensayo de Roland Barthes titulado Écrire la lecture: “¿Nunca les ha pasado, al leer un libro, interrumpir sin cesar la lectura, no por desinterés, sino al contrario por una afluencia de ideas, de excitaciones, de asociaciones? En una palabra, ¿no les ha pasado leer levantando la cabeza?” (2002b, p. 602). La figura que evoca Barthes deja bien en claro la ligazón entre lectura e interrupción, en cuanto esta última ocurre de manera, digamos, simultánea a la primera: se interrumpe sin cesar; se lee -Barthes utiliza aquí lo que en español implicaría un gerundio- levantando (en levant) la cabeza. Esta imagen nos conduce a doblar la apuesta para pensar la lectura como interrupción. Al lado de esta figura, podríamos aun ubicar otra del propio Barthes, quien afirmaba a propósito 
de la literatura lo que podríamos decir respecto de la lectura: "la literatura [la lectura, diríamos aquí] es como el fósforo: brilla más en el momento en que intenta morir" (2002a, p. 193).

Como ya mencionamos, nos detendremos en tres escenas de lectura, interrogando allí lo que remite a la interrupción, a las fronteras, al espacio de la lectura, avanzando lentamente e interrumpiendo, nosotros también, la lectura a cada paso.

\section{Primera escena: Sobre la lectura o la vida y la literatura}

¿Es la lectura una interrupción de la vida? ¿Es la vida una interrupción de la lectura? ¿Hay una interrupción de la vida cuando se lee? ¿Hay una interrupción de la lectura cuando el mundo exterior - para emplear una polaridad entre lo externo y lo interno, entre el afuera y el adentro, que no tardaremos en cuestionar- impide la atención sobre el libro y obliga al lector a levantar la cabeza?

En el primer tomo de $\grave{A}$ la recherche du temps perdu, Marcel se recluye en su habitación con un libro y se ve importunado por su abuela, quien exige al niño salir al jardín porque "en el campo es una pena estar encerrado" (Proust, 2004a, p. 37). La interrupción de la abuela pareciera representar esa distancia entre el encierro que hará débil al niño y el afuera del campo cuyo poderoso verano, pletórico de tormentas, lo volverá vigoroso. Para la abuela, la vida es pujante en cuanto se expone al afuera, al despliegue del verano, donde, aun cuando la lluvia es abundante, puede decir: "Por fin, respiramos" (p. 38). No obstante, metafóricamente, como nos ha enseñado Paul de Man (Allegories), el "total espectáculo del verano" (Proust, 2004a, p. 80) en la casa de Combray no es experimentado afuera, donde lo sería fragmentariamente, sino en el cuarto con el libro en la mano. ¿Dónde está el verano para Marcel? La pregunta es problemática porque el dónde presupone una topografía intra y otra extra textual, una intra y otra extra literaria. ¿Interrumpe la abuela -y el verano que parece evocarse en el afuera de la casa, transportado al interior de la habitación por la fuerza metonímica de las moscas que lo portan en sí como pequeños fragmentos de su totalidad- la lectura de Marcel? ¿Interrumpe, a su vez, la lectura, la vida del verano, cuyo efecto Marcel pierde al evitar el sol en el encierro de su cuarto? ¿Qué verano? ¿El fragmentario, según Paul de Man, que Marcel viviría siguiendo los consejos de su abuela o el total, espectacularizado en la experiencia de lectura? ${ }^{2}$

\footnotetext{
${ }^{2}$ Esta tensión entre el afuera y el adentro aparece también en muchas pinturas que retratan la lectura. Si con frecuencia el lugar de la pintura es la habitación -espacio de lo íntimo y privado, a veces, también, de lo erótico (cf. por ejemplo el cuadro $L a$ liseuse de romans (1885), de Antoine Wirtz)-, en muchas ocasiones se expresa un entrelazamiento del universo del lector y la naturaleza, frecuentemente de tono bucólico, solapando un adentro y un afuera del libro: An Elegant Lady Reading under a
} 
Estas preguntas no deberían llevarnos a una conclusión ingenua, tan cara a algunos espíritus románticos, y desplegar el terreno de lo literario hacia la vida en su totalidad, como si un verano y el otro fueran equivalentes. Pero tampoco a la no menos ingenua percepción que crea posible separar sin más el mundo de la literatura y el otro que llamamos vida: un verano y otro son ficciones en la medida en que epistemológicamente uno y otro están sujetos a una construcción no solo cognitiva sino también, y quizás sobre todo, afectiva (Damasio, 2017). Un verano y otro interactúan, se modelan, ligan, digámoslo, intertextualmente sus mundos.

¿Qué podría ser entonces la interrupción y qué mundo interrumpe cuál? ¿La interrupción es el síntoma de una frontera entre el universo del texto y otro por fuera de él? Es este vínculo tan estrecho entre el adentro y el afuera, entre la vida y la lectura, cuya separación es cuestionada, lo que advierte el propio Proust al comienzo de Sur la lecture, en la primera escena de lectura que quisiéramos aquí evocar:

Quizás no hay días de nuestra infancia tan plenamente vividos como aquellos que hemos creído dejar sin vivirlos, los que pasamos con un libro preferido. Todo lo que, al parecer, colmaba a los demás, y que nosotros apartábamos como un obstáculo vulgar para un placer divino: el juego para el que un amigo venía a buscarnos en el pasaje más interesante, la abeja o el rayo de sol molestos que nos forzaban a levantar los ojos de la página o a cambiar de lugar; las provisiones para la merienda que nos habían hecho traer y que dejábamos a nuestro lado en el banco, sin tocarlas, mientras que, sobre nuestra cabeza, disminuía la fuerza del sol en el cielo azul; la cena para la que había que volver a casa y durante la cual no pensábamos en otra cosa que en subir a terminar enseguida el capítulo interrumpido; todo eso -en lo que la lectura hubiera debido impedirnos ver otra cosa que la importunidad-grababa en nosotros, por el contrario, un recuerdo tan dulce (mucho más preciado a nuestro juicio actual que aquel que leíamos entonces con tanto amor) que, si nos sucede hoy hojear esos libros de antaño, lo hacemos sólo por ser los únicos calendarios que hemos conservado de los días ya pasados, y con la esperanza

Tree (Karl Raupp, 1874), Dans la praire (Claude Monet, 1876), Girl Reading (Charles Edward Perugini, 1878), The Complete Angler (Arthur Hughes, 1884), The Lane (Theodore Robinson, 1893), La lecture au jardin (Henri Lebasque, 1908-1910), A Girl Reading in a Hammock (Robert Archibalt Graafland, 1910), In the Garden (Carl Spitzweg, 1938). En esta lista aleatoria, que incluye en gran parte obras impresionistas y posimpresionistas, la lectura se desplaza de la intimidad reservada de la habitación a la exuberancia no menos pacífica del jardín o el parque, en una tensión que en algunos casos sitúa a los lectores en la bisagra del afuera y el adentro: At the Window (Hans Olaf Heyerdahl, 1881), Portrait of Anna Goeneutte Wearing a Beret (Norbert Goeneutte, 1889), Summer Dreams (Sergei Arsenevich Vinogradov, 1915). En estas últimas pinturas citadas, vemos lectoras junto a una ventana en distintas posiciones, bien sumergidas en el libro, bien con la vista perdida hacia algo que sucede más allá de los límites de la casa, pero siempre ubicadas en la frontera entre el afuera y el adentro. 
de ver reflejados en sus páginas las moradas y los estanques que ya no existen (1987, pp. 39-40).

Avancemos de a poco, porque la escena es compleja y se resiste a una interpretación rápida. En primer lugar, porque comienza por una suerte de paradoja que permanece latente todo a lo largo del fragmento: el momento más plenamente vivido es aquel donde creímos haber dejado de vivir. Incluso la enumeración de los obstáculos que se manifiestan inicialmente como perturbaciones a la lectura son aquellos que más podrían ligarse a la vida como tal: el juego, el sol, la naturaleza (las abejas), las provisiones alimentarias. ¿No componen estos elementos aunque se extrañaría la sexualidad, si bien Serge Doubrovsky (1974) la ha encontrado en Proust detrás de los alimentos- el campo semántico de la vida y, aún, del deseo en cuanto es lo que, al parecer, colmaba a los demás? Al parecer: ¿son esos elementos un engaño, una distracción del verdadero placer, el que verdaderamente -y no al parecer-colma? El juego, el sol, la naturaleza, el alimento, obstáculos a un placer divino, verdadero costado de la vida que se encuentra, entonces, en el campo de la lectura. Pero, ¡sorpresa!, en segundo lugar, como en un vaivén que nos devuelve al inicio, engañados por apariencias y matices (“quizás", “creímos”, "al parecer”), la lectura es donde la vida infantil más plenamente se ha experimentado porque ella funciona como un calendario único que es capaz de "reflejar" todo eso que ya no existe: las moradas y los estanques, pero también los obstáculos a la lectura, el juego, el sol, la naturaleza, el alimento. Se experimenta la plenitud de la vida por un rodeo: el de la lectura, suerte de campo magnético que adhiere a sí los días pasados y sus placeres.

La lectura estiliza la vida, aun allí donde esta última pareciera ser su obstáculo, plagando de mundanidades fastidiosas el espacio íntimo en el que se produce el encuentro con el libro. La lectura se liga a la vida, incluso allí donde creímos haber dejado de vivir los momentos en que un estado de absorción pareciera cerrar la frontera entre el mundo y el texto, entre el libro y los objetos mundanos. Pero, ¿cuál es entonces la naturaleza de esos objetos que al parecer pertenecen a un mundo externo, al mundo del afuera?

En The Ethics of Reading (1987), Joseph Hillis Miller afirma que en todo texto hay un imperativo ético: "Los textos demandan que el lector salga afuera del texto" (1987, p. 3). Es decir, exigen que el lector abandone el texto y compruebe su validez referencial y performativa. El texto reclama imperativamente la interrupción de la lectura en pos de su verificación. Pide al lector que constate lo dicho por fuera de lo dicho, más allá de sus propios límites tangibles. ¿Sería entonces esta interrupción el momento en que el universo lingüístico del texto se abandona para verificar ya su correspondencia con el mundo fenomenal, ya la verdad de su 
sentido aprehendido desde una exterioridad capaz de totalizarlo? Sin embargo, el fragmento de Proust nos indica la insuficiencia de esta separación, allí donde lo que se ha dejado de vivir es en realidad lo plenamente vivido.

Miller avanza todavía más: lo que sucede cuando el lector responde a esa demanda es la experiencia de la imposibilidad de verificar la verdad de un texto. Porque todo texto está habitado por aporías que impiden su legibilidad: siempre existen sentidos igualmente legítimos que entran en contradicción, atentando contra la verificación referencial. En todo caso, en el movimiento del lector que se dirige desde el texto hacia el mundo, desde dentro hacia afuera, lo que se descubre es una falta de coincidencia entre el objeto y el referente, según la separación que establece Paul de Man al definir la ideología: "Lo que llamamos ideología es precisamente la confusión de la realidad lingüística con la natural, de la referencia con el fenomenalismo" (2002, p. 11). Por ello, la interrupción de la lectura no es el punto de quiebre entre el signo y el objeto; no es el universo lingüístico lo que resulta abandonado en una interrupción que devuelve al lector al mundo del fenomenalismo.

Si la vida se entromete en la lectura, a la vez la constituye: lo que queda de la lectura es precisamente esa interrupción. Si la lectura interrumpe la vida, a la vez la constituye: lo que queda de la vida es su resonancia - para evitar, en todo caso, la tan problemática noción de "reflejo" que utiliza Proust-, incluso su reescritura (la de los días pasados) a través de la literatura.

Esta escena de Proust nos advierte así sobre la rareza de hablar en términos de interrupción de la lectura toda vez que con esa figura separemos la literatura de la vida, toda vez que represente la lectura como un encuentro a solas del lector con el libro. Antes bien, pareciera que la interrupción es inherente a la lectura; incluso en aquellos escritores como Proust donde la interrupción parece ser el obstáculo a la agradable soledad lectora.

No están de un lado la vida y del otro la lectura. La lectura es un acontecimiento que ocurre según un modo de ser, según un modo de vivir; Façons de lire, manières d'être, reza el título de un libro de Marielle Macé (2011). Leemos de acuerdo a un estilo de comportamiento: leemos de la misma manera que amamos o caminamos. Pero también la lectura estiliza nuestra vida, reconfigura las preguntas que le dirigimos al mundo, el paradigma desde el cual lo percibimos y el particular talante con el que actuamos en él; aun cuando algo en nosotros permanece inalterable y resistente a la interpretación, como sucede con la propia literatura. Porque la interrupción de la lectura no es el hiato de la discontinuidad entre la literatura y la 
vida. Al contrario, es la manifestación, la verificación, de una continuidad constitutiva entre una y otra.

\section{Segunda escena: La tardecita o el inconsciente y la literatura}

Si Proust nos permite ponderar la dificultad en separar la vida -concebida en su sentido más amplio como el universo externo al del libro en el que el sujeto experimenta su cotidianeidad-y la literatura, quisiéramos circunscribir ahora el interés a la implicancia de la subjetividad y el inconsciente. La interrupción, contra todo deseo positivista, se vincula aquí a la presencia subjetiva del lector: su vida, sus deseos, su pasado, sus fantasmas. La interrupción se define en este caso como la implicación del sujeto en la lectura.

Como en Proust, encontramos también la resonancia del pasado a través de la lectura en nuestra segunda escena, perteneciente a un breve relato de Juan José Saer titulado "La tardecita" (2012): un domingo por la mañana, Barco, sabiendo que su amigo Tomatis llegará para el almuerzo, aprovecha la espera para leer y elige un texto relativamente corto de Petrarca, con el objetivo de terminarlo antes del mediodía. Durante su lectura, Barco se ve súbitamente sorprendido por un recuerdo de infancia, que surge como consecuencia de una asociación con el ascenso de Petrarca al monte Ventoux. Nos dice entonces el narrador:

Existe siempre durante el acto de leer un momento, intenso y plácido a la vez, en el que la lectura se trasciende a sí misma, y en el que, por distintos caminos, el lector, descubriéndose en lo que lee, abandona el libro y se queda absorto en la parte ignorada de su propio ser que la lectura le ha revelado: desde cualquier punto, próximo o remoto, del tiempo o del espacio, lo escrito llega para avivar la llamita oculta de algo que, sin él saberlo tal vez, ardía ya en el lector (p. 57; subrayado propio).

La extensión del poema de Petrarca -que Barco pondera objetivamente según un período de tiempo cronológico que va de la mañana al mediodía- se extiende subjetivamente en el tiempo y el espacio por asociaciones establecidas a causa de una "parte ignorada de su propio ser”. La lectura no se interrumpe por el recuerdo evocado; la experiencia que lo conduce a su infancia está allí simultáneamente y se hace consciente en un momento "durante el acto de leer". Lo que se abandona es el libro, no la lectura que continúa en su transcendencia, llevando al lector a una suerte de revelación. El lenguaje místico que apreciábamos en Proust a partir de la idea de un placer divino reaparece aquí bajo el fenómeno de la trascendencia y la revelación. El recuerdo sorprende a un lector que se ve de pronto desbordado por la intensidad y el placer 
de lo que, a pesar de propio e íntimo, le resulta desconocido. ¿No tenemos allí un verdadero acontecimiento psíquico, cercano a lo que el psicoanálisis deja traslucir con la idea de una verdad que nos habla en lo reprimido que retorna? ¿No es la interrupción, precisamente, el momento en el que esa verdad psíquica se propone hablar?

Lo que interrumpe aquí ya no es el mundo de la vida como expresión de un afuera que rodea al sujeto y obstaculiza su lectura; lo que interrumpe ahora es también inoportuno pero en la medida en que el lector no lo espera, lo sorprende, incluso lo molesta al punto del desconocimiento: ¡ese de ahí no soy yo! Otra vez el desborde -como si el gesto fuera el reflejo propio de la interrupción- conduce a levantar la cabeza:

Barco - dice el narrador-alzó la vista del libro y, con los ojos bien abiertos que no veían sin embargo nada del exterior, la fijó en algún punto impreciso de la habitación y se quedó completamente inmóvil, lleno hasta rebalsar del recuerdo que la lectura había suscitado (Saer, 2012, p. 57).

Lo que rebalsa no es solo el lector, cuyos límites se vuelven difusos en el momento en que advierte zonas ignotas de su propio ser; lo que rebalsa es también el libro, cuyo espacio se fractura y extiende por un espacio-tiempo particular en el que habitamos durante la experiencia de la lectura. Al referirnos a este espacio-tiempo particular, nos vemos tentados a preguntar: ¿dónde y cuándo ocurre la lectura como interrupción? La lectura ocurre precisamente en un espacio que, siguiendo a Donald Winnicott, podemos llamar transicional:

Introduzco los términos “objetos transicionales" y "fenómenos transicionales" para designar la zona intermedia de experiencia, (...) entre la actividad creadora primaria y la proyección de lo que ya se ha integrado. (...) Una zona intermedia de experiencia a la cual contribuyen la realidad interior y la vida exterior. (...) Zona intermedia entre lo subjetivo y lo que se percibe en forma objetiva (1971, pp. 18-19).

Se trata de una zona donde se desarrolla la mayor parte de las vivencias del bebé, pero que "se conserva a lo largo de la vida en las intensas experiencias que corresponden a las artes y la religión, a la vida imaginativa y a la labor científica" (Winnicott, 1971, p. 32). Zona tercera de la vida humana que a partir de la infancia regula la relación del sujeto con el mundo, cognitiva y afectivamente.

No es sorprendente por ello que numerosos autores que han teorizado sobre la lectura, particularmente desde el campo psicoanalítico, hayan prestado atención a esta noción, como Norman Holland o Michel Picard. El primero de ellos alude explícitamente a ella en Poems in 
Persons (1973), empleando indistintamente espacio transicional y espacio potencial. Al explicar el principio según el cual la lectura es un proceso transaccional de recreación de la propia identidad, Holland afirma que:

El lector y la obra se mezclan y combinan en un espacio potencial entre quien percibe y lo percibido, donde las distinciones entre yo y otro, adentro y afuera, objeto creado y objeto encontrado, realidad objetiva y símbolo creado, dejan de tener importancia (1973, p. 146).

Por su parte, en La lecture comme jeu (1968), Michel Picard evoca el espacio transicional winnicotiano como el lugar en el que se experimenta la lectura pensada como un juego adaptativo entre lo fantasmático y lo real. Para Picard, la lectura es un juego con significantes que articulan el afuera y el adentro, entre la historia y $m i$ historia. Por un una parte, los significantes textuales conducen a las "estructuras lógico-semánticas generales de significados que pertenecen claramente a la cultura del momento y a las ideologías dominantes" (Picard, 1968, p. 51); por otra, "reenvían simultáneamente al lector a su historia personal" de tal modo que "los significantes son también aquellos de sus preocupaciones más secretas y menos conscientes" (ibidem).

En este espacio, el acontecimiento de la lectura pueda tal vez ser pensado precisamente como el momento en el que algo de la subjetividad -un elemento metonímicamente pujante: parte desconocida de sí- emerge con el poder de la interrupción en un espacio-tiempo que no es ni el del texto ni el del lector, sino el entramado de ambos. ¿Qué es entonces lo que interrumpe? Volvamos a Saer: un recuerdo. Ya no de los objetos mundanos que asociativamente se han adherido a un episodio de lectura y que, a través de ellos, evocan los placeres vividos y los momentos y objetos que ya no existen. El recuerdo, su interrupción, su irrupción, contiene su poder, lo veremos inmediatamente, en la fuerza de lo inesperado, lo desconocido que es, sin embargo, lo propio. ¿Qué recuerdo sorprende a Barco durante su lectura?

Un atardecer durante la Semana Santa, junto a su hermano cuatro años mayor, Barco camina lentamente por una llanura desierta desde el punto en el que el colectivo de Rosario los ha dejado hasta el pueblo donde pasa las vacaciones su familia. Es una caminata larga y silenciosa surcada por una tensión irresuelta, acompañada por el disco rojo del sol que va apagándose paulatinamente y que lo deja en un estado de calma intranquilidad:

Al cabo de un rato de marcha -nos dice de pronto el narrador- a la izquierda del camino, a unos cien metros adelante, divisaron el cementerio. Por temor de percibir en él el 
mismo terror apagado que empezaba a invadirlo, Barco no se animaba a mirar a su hermano, ni siquiera de reojo, y fue en ese momento en que se dio cuenta de que la llanura, en ese lugar que había atravesado decenas de veces, idéntico por otra parte a muchos otros en sesenta o setenta kilómetros a la redonda - camino de tierra, alambrado, maizales, campitos de pastoreo, redondel rojo enorme al atardecer, cuadrado de muros blancos del cementerio y cipreses negros sobrepasándolos, de habitual que había sido hasta ese momento, se estaba volviendo irreconocible y extraño (Saer, 2012, p. 59).

Lo que recuerda es una tarde en la que experimenta algo habitual, algo, digamos, familiar, que se ha vuelto extraño: ¿no es esa acaso la experiencia que Sigmund Freud (1992) define como lo ominoso? Lo ominoso: lo reprimido que retorna, la irrupción de lo inconsciente. Lo que retorna es algo que ha sido primeramente olvidado y que la lectura vuelve a evocar bajo el empuje de una verdad psíquica que surge como revelación:

Durante años sentiría el malestar de esa revelación que, gradualmente, capas y capas de experiencia, como sucesivas manos de pintura sobre una imagen odiosa, terminarían por hacérsela olvidar, hasta que esa mañana la lectura de Petrarca la trajo de nuevo a la luz viva del recuerdo (Saer, 2012, p. 59).

La estilización de la vida opera en cada acto de lectura, que parece ejecutar performativamente no los objetos mundanos sino algo que rehúye la simbolización y se nos representa como extraño, aun ahí donde es precisamente lo íntimo. La lectura es así la interrupción del inconsciente como un acontecimiento de desborde que llega como una suerte de revelación sobre aquello íntimo que ignoramos, en un espacio paradójico, ni afuera ni adentro, ni externo ni interno; antes bien, como tan poderosamente lo expresa un neologismo sugerido por Jacques Lacan (1990) para problematizar estas oposiciones: éxtimo.

\section{Tercera escena: Continuidad de los parques o la realidad y la literatura}

A fuerza de repetición, nuestra última escena nos permite apercibirnos de algo: el lector busca evitar las interrupciones que incomodarían la lectura; pero la interrupción proviene de un lugar inesperado, precisamente porque la lectura es la irrupción de lo que no se espera. Con Proust, la interrupción refería a las relaciones de continuidad entre la vida y la literatura; en Saer, la interrupción daba cuenta de la irrupción del inconsciente y los lazos de continuidad entre el texto y el lector; ahora, con Julio Cortázar, veremos cómo la interrupción manifiesta los vínculos que entrelazan la realidad y la ficción. 
En "Continuidad de los parques" (2004), el lector, sentado en su sillón de terciopelo verde, es interrumpido por aquello mismo que lee, reconfigurando los niveles que separan un mundo de otro en una espiral vertiginosa, acaso trágica. Encontramos quizás en esta escena la imagen tangible de lo que significa la lectura como interrupción. Nos permitimos, por eso, repetirlo: el lector es interrumpido por aquello mismo que lee. Parece un enunciado tramposo, paradójico, contradictorio: ¿cómo se interrumpe algo a sí mismo? ¿Cómo puede la continuidad abrirse a sí misma en lo discontinuo? Como una banda de Moebius, la lectura y la interrupción parecen habitar el mismo plano y otro a la vez.

Un hombre se dispone a leer una novela y procura entonces, antes de comenzar, desembarazarse de todo aquello que pueda ser un obstáculo a su lectura, que pueda interrumpir el estado de absorción en el que se sumerge al leer una novela, aquello que ya lo ha obligado a abandonarla "por motivos urgentes". Inmediatamente, se sienta en su sillón favorito "de espaldas a la puerta que lo hubiera molestado como una irritante posibilidad de intrusiones" (2004, p. 417). Una vez cómodamente instalado, protegido, cree él, de todo accidente que pudiera interrumpirlo, se deja absorber por la ilusión de la ficción:

La ilusión novelesca lo ganó casi en seguida. Gozaba del placer casi perverso de irse desgajando línea a línea de lo que lo rodeaba, y sentir a la vez que su cabeza descansaba cómodamente en el terciopelo del alto respaldo (ibidem).

Lo que lo rodea, ese afuera calmo y seguro, se desgaja línea a línea, como si tal espacio estuviese compuesto de capas (¿narrativas?) que pueden desprenderse una de otra. Lo gana entonces una "ilusión": ¿de qué ilusión se trata?, ¿es la ficción novelesca una ilusión frente a la realidad que lo rodea?

Esta concepción de la ilusión romanesca a la que refiere el narrador remite a la noción de "suspensión voluntaria de la credulidad" propuesta por Samuel Taylor Coleridge (2010), al hablar de la fe poética que exige el universo ficcional. Norman Holland ha incluso avanzado más lejos en la teorización de este concepto, procurando explicarlo no solo desde el punto de vista psicoanalítico (1968), sino también, recientemente, neuropsicoanalítico (2015). Para Holland, cuando leemos una obra de arte nos introducimos en su mundo olvidando todo lo que la rodea. La experiencia estética es el resultado del divorcio entre la experiencia literaria y las acciones que afectan el mundo externo, a partir del cual nos fusionamos con la obra en una suerte de regresión infantil "en el que, de acuerdo a la teoría psicoanalítica, el niño siente que los límites entre él y su madre son inciertos, permeables, confusos" (Holland, 2015, p. 115). En The Dynamics of Literary Response, el teórico norteamericano señala que cuando suspendemos 
la incredulidad en un texto literario dejamos de percibir nuestro entorno a la vez que respondemos emocionalmente a la ficción como si fuese real. Y agrega que "es precisamente nuestro conocimiento consciente de que estamos lidiando con lo irreal lo que hace posible que nos relajemos, que suspendamos nuestra incredulidad y que respondamos a lo que es irreal como si fuese real" (1968, p. 71). Como el sueño, el arte ofrecería así un espacio seguro -un espacio transicional- en el que el sujeto puede hacer jugar sus fantasías y ansiedades sin el riesgo que conlleva el mundo "real". Experiencia que, según Holland, permite la reconstrucción de la identidad de cada lector. Así, la fusión entre un universo y el otro no es más que un engaño, una ilusión, por lo demás conscientemente consentida por el lector quien sabe, o cree saber, que no hay allí ningún peligro: se desgaja línea a línea de lo que lo rodea, consciente al mismo tiempo de que su cabeza descansa cómodamente en el terciopelo del alto respaldo.

Sin embargo -hiperbólicamente figurado, es cierto-, "Continuidad de los parques" cuestiona la naturaleza segura de ese espacio entre dos que constituye la experiencia estética, llamando la atención sobre las tangibles interacciones y transformaciones que se producen entre un mundo y el otro. Algo de lo que, por lo demás, sobran los ejemplos, provenientes tanto de un universo como del otro: desde los suicidios producidos por Los sufrimientos del joven Werther de W. Goethe hasta las hilarantes preocupaciones del discurso médico durante el siglo XIX por los efectos de la lectura (Littau, 2008); desde la locura del Quijote al inocente miedo de los provincianos que asisten a la representación del Fausto en el Teatro Colón de Buenos Aires. ¿Cómo separar un universo del otro? ¿En qué medida la noción misma de espacio transicional no pone ya en jaque toda forma de delimitación entre una realidad y otra?

Thomas Pavel (1988) señala que hay dos perspectivas frente a las relaciones entre el "mundo real" y el "mundo de la ficción". Por un lado, los segregacionista, Bertrand Russell por ejemplo, consideran el contenido de las obras ficcionales como un producto de la imaginación, carentes de valor de verdad. Por otro lado, los integracionistas, como Pierre Bayard, afirman que no existe ninguna verdadera diferencia ontológica que separe la ficción de las descripciones no ficcionales del universo. Así, retiran el lugar privilegiado de la verdad en una supuesta realidad contraria a la ficción. Diluyen de este modo las fronteras entre la ficción y otros tipos de discursos. En favor de esta segunda perspectiva, Bayard (2008) pondera en L'affaire du chien des Baskerville dos argumentos. El primero, de orden lingüístico: "el lenguaje no permite hacer la separación entre los seres reales y los personajes imaginarios y la integración de estos es entonces inevitable. (...) El lenguaje es un factor permanente de interferencia de mundos" (pp. 117-118). El segundo, de orden psicológico: que los personajes no tengan realidad material 
no significa que carezcan de materialidad psicológica. Se sabe conscientemente que esos personajes no existen. Pero no ocurre lo mismo para el inconsciente. Un personaje de ficción puede influenciar la vida de una persona, llegando incluso hasta lo trágico. El psicoanálisis experimenta esta especial condición del inconsciente durante las sesiones analíticas, como ya lo señala Bayard: "somos comúnmente para los otros -sobre todo si nos situamos en una relación transferencial- personajes de ficción (...), las personas de la realidad nos llegan a través del prisma de una novela en la que son héroes o monstruos" (p. 119).

Ciertamente, es lo que sucede en "Continuidad de los parques", donde la metalepsis confunde los planos entre ficción y realidad, y la zona transicional -espacio supuestamente seguro en el que, de acuerdo a Holland (1973), nos entregamos a la ilusión sin correr riesgosse convierte en la escena misma del crimen. Exhibiendo las fronteras difusas de los universos, el cuento de Cortázar expresa la imposibilidad del metalenguaje (el lector está siempre de algún modo comprometido e inscrito en lo que lee, porque la naturaleza lingüística que atraviesa ambos mundos no permite situarse en un punto externo y porque la experiencia psíquica implicada en la lectura desconoce las fronteras) a la vez que discute el estatuto epistemológico de la separación entre el universo del texto y el universo del lector. Tal es la razón por la cual alguien como Algirdas Greimas ha llegado a sostener que "Continuidad de los parques" "es el esbozo de una teoría de la literatura" (1987, p. 55).

Un esbozo, además, de una teoría de la lectura: aquella que indaga las relaciones de continuidad y discontinuidad topológica en el que ocurre la lectura. He aquí lo que el relato de Cortázar pone en escena: la ilusión presente en la experiencia de lectura no es la que por un momento determinado suspende la incredulidad y asume la posible existencia de una realidad que no existe. Todo lo contrario: la ilusión es el engaño de asumir que existe una división entre los mundos y que la interrupción puede provenir de un afuera. La lectura, insistimos, es precisamente la interrupción que proviene del universo en el que ya estamos sumergidos. La lectura es el acontecimiento en el cual algo de lo leído nos toca, nos sorprende, nos desborda, se interrumpe a sí mismo por su poder de evocación y transformación. Como el fósforo para Barthes, muere en el instante preciso en que brilla en su esplendor.

\section{Conclusión: la lectura como interrupción}

Hay un cuadro de Robert James Gordon en el que una mujer, sentada bajo la sombra de un árbol -en un espacio en el que conviven una piel profundamente blanca que no parece recibir 
el efecto del sol y una tupida naturaleza-, interrumpe un momento su lectura -señalando con el dedo índice el punto exacto en el que se ha detenido-y mira hacia un costado, más allá de los límites de la pintura, en un punto distante que nos interroga: ¿hacia dónde mira?, ¿algo externo que llama su atención ha interrumpido su lectura? Sin embargo, la pintura lleva el siguiente título: Woman Reading (1871).

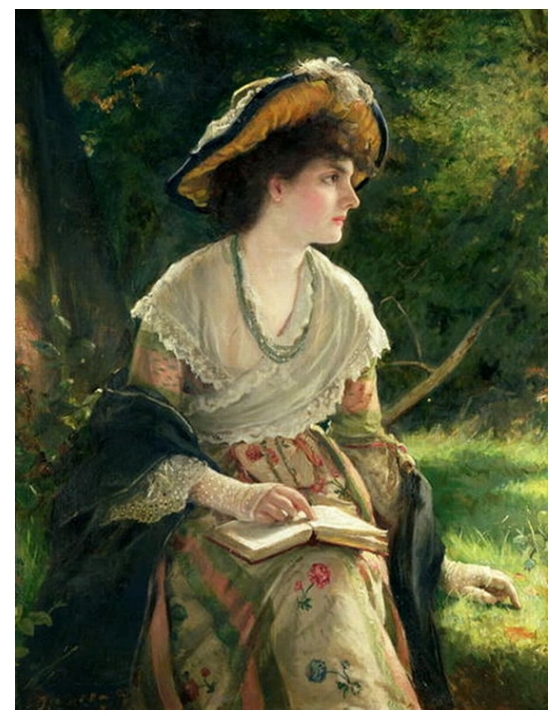

\section{Woman Reading (1871), de Robert James Gordon}

Mujer leyendo. ¿Continúa entonces la lectura? ¿Marca el gerundio que la lectura no ha sido interrumpida? O más bien: ¿marca el gerundio, su continuidad, que esa interrupción es el instante preciso de la lectura? Las escenas que hemos recorrido en este ensayo, acudiendo a la literatura para indagar allí lo que ella tiene para decirnos sobre el leer, nos permiten arriesgar una respuesta afirmativa para esta última pregunta. El gerundio en el cuadro de James Gordon ilustra significativamente la idea de la lectura como una experiencia de interrupción.

Se trata de una figura con la que aludimos a (una puesta en cuestión de) las relaciones que se establecen durante la lectura entre el mundo de la vida y el de la literatura (Proust), entre el inconsciente y la literatura (Saer), entre la "realidad" y la literatura (Cortázar). La lectura como interrupción no es la interrupción de la lectura. ¿Qué podría significar la interrupción de la lectura si ella, la lectura, es ya una interrupción? ¿Una interrupción de qué? De sí y de lo otro; de la vida y de la literatura. Pero la figura parece contradecirse, se deshace en el momento en que demuestra su punto: porque la lectura como interrupción denuncia la ilusión de una separación clara entre la literatura y la vida, entre el lector y el texto, entre la ficción y la realidad. 
La lectura como interrupción significa el desbordamiento, lo inesperado, el accidente, lo que altera el curso continuado del leer, lo que altera el curso continuado de la vida. Podríamos decir, para volver a Paul de Man (The Resistance): la resistencia. Levantar la cabeza es un gesto que surge como consecuencia de algo que se resiste, que no se deja dominar, que desgarra la legibilidad, el cierre, la clausura. Pero levantar la cabeza es también un gesto que surge como consecuencia de un pasaje a la escritura, del decir, de la expresión de sí, precisamente por el anudamiento entre la vida del sujeto lector (con su historia y su inconsciente) y la literatura. ${ }^{3}$

Por ello mismo, la lectura como interrupción debería significar, finalmente, la lectura como un pasaje a la escritura, que ocurre incesantemente, dando lugar a una suerte de paradoja: la interrupción incesante. Tal era la relación de Roland Barthes con la Recherche de Proust, de la que decía que su placer radicaba en que nunca se saltaban los mismos pasajes (Barthes, 2002c). ¿Será entonces la interrupción la figura que designa la incesante escritura de la vida a través de la literatura?

Barthes acude una tarde de 1978, por primera vez, a ver al gran bailarín ruso Rudolf Noureev, cuyo genio es aclamado en Francia. Al comenzar el espectáculo, la danza ordinaria de la que es espectador y la decepción concomitante lo llevan a dudar de que se trate de Noureev: "no puede ser él, las estrellas nunca aparecen al comienzo". Pero en el entreacto, un amigo le hace saber que se trataba efectivamente del bailarín que conmociona a toda Francia. Al volver a entrar, Barthes parece ver otra cosa, y cada ovación le parece justificada, el genio del bailarín lo deja estupefacto: "Me daba cuenta entonces - nos dice- que acababa de reproducir, en 1978, la escena en la que el narrador proustiano va un día a ver tocar la Berma". Todo está allí para Barthes, literalmente: el deseo, la espera, la decepción, la conversión, los movimientos del público. Sale del espectáculo maravillado, conmovido, no tanto por Noureev como por Proust: "no cesamos de aumentar la Recherche (como Proust lo hacía con sus manuscritos), no cesamos de escribirla. Y, sin duda, eso es la lectura: reescribir el texto de la obra a través del texto de nuestra vida" (Barthes, 2002d, p. 628).

\footnotetext{
${ }^{3}$ La interrupción que trabajamos en este ensayo contempla la simultaneidad que entrelaza un mundo y otro, diluyendo las fronteras que lo separan. Es decir, la interrupción que ocurre durante el acto de leer como efecto de la inscripción del sujeto en la lectura. Investigación aparte, y complementaria, merece la interrupción vinculada a la materialidad del texto, tanto en su extensión (las interrupciones forzadas por la longitud del texto que se expresan en la existencia de artefactos como el marcador) como en su profundidad (las interrupciones vinculadas a los soportes hipertextuales, estimuladas por la propia composición del texto a través de los hipervínculos).

${ }^{4}$ Barthes se refiere al episodio en que el narrador de la Recherche, con gran expectativa primero y gran desilusión después, acude a ver la interpretación de Fedra que ejecuta "la Berma", actriz de teatro en la que Proust condensó rasgos de dos actrices francesas: Sarah Bernhardt (1844-1923) y Gabrielle Réjane (1856-1920) (cf. Proust, 2004b, pp. 285-297).
} 


\section{Referencias bibliográficas}

Barthes, Roland. (2002a). Le degré zéro de l'écriture. Euvres complètes (Tome I). París: Seuil. Barthes, Roland. (2002b). “Écrire la lecture”. Euvres complètes (Tome III). París: Seuil.

Barthes, Roland. (2002c). Le plaisir du texte. Euvres complètes (Tome IV). París: Seuil.

Barthes, Roland. (2002d). "Noureev et la Berma". CEuvres complètes (Tome V). París: Seuil.

Bayard, Pierre. (2004). Peut-on appliquer la littérature à la psychanalyse ? París: Minuit.

Bayard, Pierre. (2008). L'Affaire du Chien des Baskerville. París: Minuit.

Bernárdez, Asunción. (2007). Pintando la lectura: mujeres, libros y representación en el Siglo de Oro. Edad de oro, XXVI, 67-90.

Coleridge, Samuel Taylor. (2010). Biographia Literaria. Montana: Kessinger Publishing.

Cortázar, Julio. (2004). “Continuidad de los parques”. Cuentos Completos 1. Buenos Aires: Punto de lectura.

Damasio, Alonso. (2017). El extraño orden de las cosas. La vida, los sentimientos y la creación de las culturas. (J. Ros, trad.). Barcelona: Ediciones Destino.

De Man, Paul. (1979). Allegories of Reading. New Heaven and London: Yale University Press.

De Man, Paul. (2002). The Resistance to Theory. Minneapolis: University of Minnesota Press.

Doubrovsky, Serge. (1974). La place de la madeleine. París: Mercure de France.

Freud, Sigmund. (1992). Lo ominoso. Obras completes (Vol. XVII). (J. L. Etcheverry, trad.). Buenos Aires: Amorrortu.

Greimas, Algirdas Julien. (1987). De l’imperfection. Périgueux: Pierre Fanlac.

Holland, Norman. (1968). The Dynamics of Literary Response. New York: Oxford University Press.

Holland, Norman. (1973). Poems in persons. New York: The Northon Library.

Holland, Norman. (2015). Literatura, lectura y neuropsicoanálisis. (N. Garayalde, trad.). Córdoba: Alción.

Lacan, Jacques. (1990). El seminario. Libro 7. La ética del psicoanálisis. (D. Rabinovich, trad.). Buenos Aires: Paidós. 
Littau, Karin. (2008). Teorías de la lectura. Buenos Aires: Manantial. Trad. de Elena Marengo.

Macé, Marielle. (2011). Façons de lire, manières d'être. París: Gallimard.

Miller, Joseph Hillis. (1987). The Ethics of Reading. New York: Columbia University Press.

Pavel, Thomas. (1988). Univers de la fiction. París: Seuil.

Picard, Michel. (1968). La lecture comme jeu. París: Minuit.

Proust, Marcel. (1987). Sur la lecture. París: Complexe.

Proust, Marcel. (2004a). Por el camino de Swann. Obras completas (Tomo I). (P. Salinas, trad.). Madrid: Aguilar.

Proust, Marcel. (2004b). A la sombra de las muchachas en flor. Obras completas (Tomo II). (P. Salinas, trad.). Madrid: Aguilar.

Saer, Juan José. (2012). Lugar. Cuentos Completos (1957-2000). Buenos Aires: Seix Barral.

Winnicott, Donald. (1971). Realidad y juego. (F. Mazía, trad.). Barcelona: Gedisa.

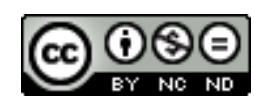

Esta obra está bajo una licencia de Creative Commons Reconocimiento-NoComercial-

\section{SinObraDerivada 4.0 Internacional}

